\title{
Parametric Study of Tuned Mass Dampers for Long Span Transmission Tower-Line System under Wind Loads
}

\author{
Li Tian and Yujie Zeng \\ School of Civil Engineering, Shandong University, Jinan, China \\ Correspondence should be addressed to Li Tian; tianli@sdu.edu.cn
}

Received 29 June 2016; Revised 17 September 2016; Accepted 3 October 2016

Academic Editor: Pedro Galvín

Copyright (C) 2016 L. Tian and Y. Zeng. This is an open access article distributed under the Creative Commons Attribution License, which permits unrestricted use, distribution, and reproduction in any medium, provided the original work is properly cited.

\begin{abstract}
A parametric study of tuned mass dampers for a long span transmission tower-line system under wind loads is done in this paper. A three-dimensional finite element model of transmission tower-line system is established by SAP2000 software to numerically verify the effectiveness of the tuned mass damper device. The wind load time history is simulated based on Kaimal spectrum by the harmony superposition method. The equations of motion of a system with tuned mass damper under wind load excitation are proposed, and the schematic of tuned mass damper is introduced. The effects of mass ratio, frequency ratio, damping ratio, the change of the sag of transmission line, and the robustness of TMD are investigated, respectively. Results show that (1) the change of mass ratio has a greater effect on the vibration reduction ratio than those of frequency ratio and damping ratio, and the best vibration reduction ratio of TMD is not the frequency ratio of $1 ;(2)$ the sag-span ratio has an insignificant effect on the vibration reduction ratio of transmission tower when the change of sag-span ratio is not large; and (3) the effect of ice should be considered when the robustness study of TMD is carried out.
\end{abstract}

\section{Introduction}

With the development of industry, transmission tower and line are more and more important as a lifeline project in power system. Its failure may lead to the outage of power supply [1]. The transmission tower-line system is very sensitive to wind loads due to its large span and high rise and being flexible. Many transmission towers are damaged due to strong wind loads in recent investigations [2]. For example, in 2002, the strong wind appeared in Liaoning province of China which resulted in the damage of many transmission towers. Due to the occurrence of the strong wind in 2005, the transmission towers are damaged seriously in Jiangsu province of China. In 2009, the transmission tower was broken owing to wind and ice in Australia. The wind-induced collapse of transmission towers is shown in Figure 1. It is of great importance to reduce the response of transmission towers and improve the reliability of transmission towers under wind loads.

A few researchers have studied the vibration control of transmission tower-line system under wind action in recent years. Wu and Yang [3] designed an active mass driver for installation on the upper observation deck of the $310 \mathrm{~m}$ Nanjing TV transmission tower in China in order to reduce the acceleration response under strong wind gusts. Furthermore, $\mathrm{Wu}$ and Yang [4] presented the linear quadratic Gaussian (LQG) control strategy using acceleration feedback to reduce the tower responses under coupled lateral torsional motion. Battista et al. [5] envisaged nonlinear pendulum-like dampers (NPLD) installed on the towers and demonstrated the efficiency with the aid of comparisons between numerical results obtained from the controlled and the uncontrolled systems. He et al. [6] proposed a suspended mass pendulum (SMP) for vibration reduction of a transmission tower. Both numerical and experimental results verified that the SMP was very effective in reducing acceleration of the tower. Chen et al. [7] carried out the control of wind-induced response of transmission tower-line system using magnetorheological (MR) dampers. The results demonstrated that the incorporation of MR dampers into the transmission tower-line system can substantially suppress the wind-induced collapse of transmission tower. In addition, Chen et al. [8] studied the vibration control and performance evaluation on a transmission tower-line system by using friction dampers subjected 

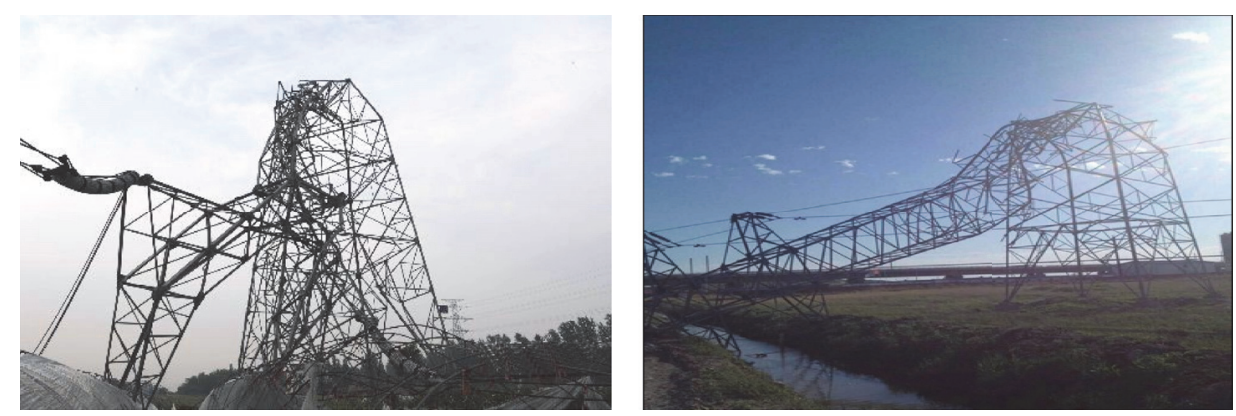

FIGURE 1: Wind-induced collapse of transmission towers.

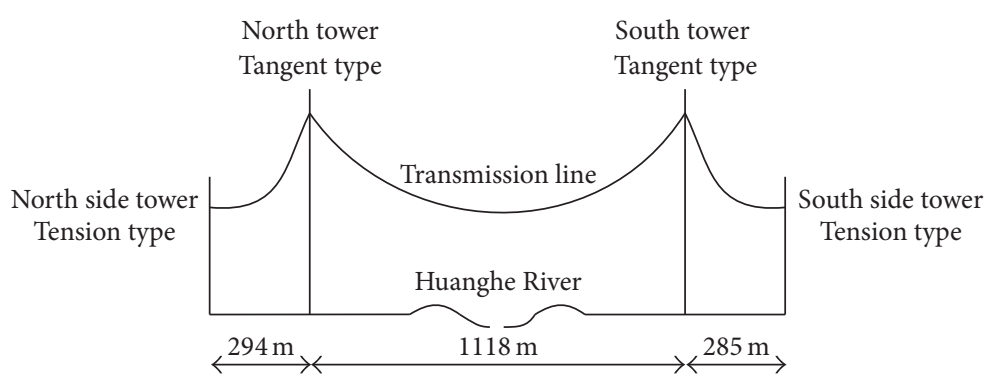

FIGURE 2: Schematic diagram of long span transmission tower-line system.

to wind excitations. The results showed the application of friction dampers with optimal parameters could significantly reduce wind-induced responses of the transmission towerline system. Zhang et al. [9] proposed the utilization of the internal resonance feature of the spring pendulum (SP) to reduce the wind-induced vibration of a transmission tower. Tian and Gai [10] proposed a new type of vibration control device, that is, pounding tuned mass damper (PTMD), and PTMD was very effective in reducing the wind-induced vibration and the vibration control performance improved as the external wind load increases. However, there are few studies about the parametric study of vibration control for long span transmission tower-line system under wind loads.

A parametric study of tuned mass damper (TMD) for long span transmission tower-line system under wind loads is investigated in this paper. A three-dimensional finite element model of long span transmission tower-line system is established by SAP2000 software based on a real project. The wind load time history is simulated by the harmony superposition method. The finite element simulation of TMD is introduced. The effects of mass ratio, frequency ratio, and damping ratio of TMD are studied, respectively. Furthermore, the effects of change of the sag of transmission line and the robustness of TMD are investigated, respectively.

\section{Structural Model}

The long span transmission tower-line system across Huanghe River in China is studied in this paper. Figure 2 gives the schematic diagram of long span transmission tower-line system. The long span transmission tower-line system consists of four transmission towers and three span transmission lines. North and south side towers are tension type, while

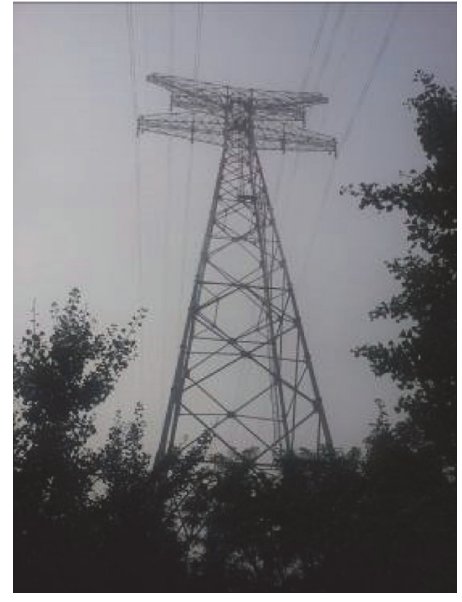

FIGURE 3: Practical graph of transmission tower-line system.

north and south towers are tangent type. The span across the Huanghe River is $1118 \mathrm{~m}$, and the north and south side spans are $294 \mathrm{~m}$ and $285 \mathrm{~m}$, respectively. Figure 3 gives the practical graph of transmission tower-line system. The size of tangent tower with the total height of $122 \mathrm{~m}$ is shown in Figure 4. The structural members of the transmission tower are made of steel tube with $206 \mathrm{Gpa}$ elastic modulus. The type of the upper two ground lines is OPGW-180 and the type of the lower six two-bundled conductor lines is LHBGJ-400/95. The threedimensional finite model of the coupled transmission towerline system is established by SAP2000 software as shown in Figure 5. The beam and cable element are selected for the simulation of transmission tower and line, respectively. The base points of the transmission tower are assumed to be fixed 


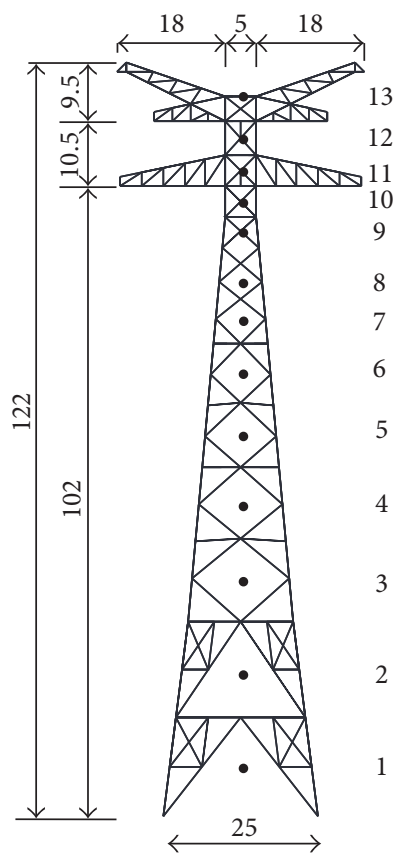

Figure 4: Tower size (m).

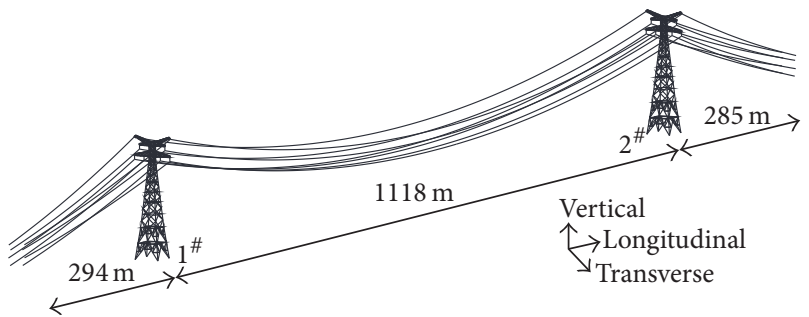

Figure 5: Three-dimensional finite model of the long span transmission tower-line coupled system.

and the connections between transmission towers and lines are hinged by insulators. As shown in Figure 5, the wind angle of $0^{\circ}$ can be assumed as the longitudinal direction along the transmission line, while the wind angle of $90^{\circ}$ can be assumed as the transverse direction perpendicular to the transmission line.

\section{Wind Load Simulation}

The wind excitations of transmission tower-line system are simulated by harmony superposition method [11, 12]. The target power spectrum is Kaimal fluctuating wind power spectrum [13]. Wind is generated due to the air flow in the atmospheric boundary layer. The movement of the wind field is a heterogeneous random process related to the space and time. Wind velocity profile is used to describe the variation of the mean wind along the height. The logarithmic function is used to calculate the mean wind and can be expressed as

$$
\bar{v}(z)=\frac{1}{k} u_{*} \ln \left(\frac{z}{z_{0}}\right),
$$

TABLE 1: The positions of wind load and windward area.

\begin{tabular}{lcc}
\hline Points & Height $(\mathrm{m})$ & Windward area $\left(\mathrm{m}^{2}\right)$ \\
\hline 1 & 8 & 21.66 \\
2 & 23.75 & 17.81 \\
3 & 38.5 & 13.39 \\
4 & 50.5 & 11.62 \\
5 & 61.5 & 8.21 \\
6 & 71.5 & 7.80 \\
7 & 80.5 & 5.11 \\
8 & 86.5 & 4.15 \\
9 & 92 & 5.72 \\
10 & 99.5 & 3.49 \\
11 & 104.5 & 13.93 \\
12 & 109.75 & 3.35 \\
13 & 116.5 & 15.66 \\
\hline
\end{tabular}

where $z$ is the standard height. $k$ is the Karman constant equal to $0.4 . \bar{v}(z)$ is the mean wind speed at the height of $z \cdot z_{0}$ is the roughness length. $u_{*}$ is the friction velocity.

The Kaimal spectrum is adopted as target spectrum to simulated turbulent wind for the high transmission tower. The Kaimal spectrum can be expressed as

$$
\frac{n S_{v}(n)}{u_{*}}=\frac{200 x}{(1+50 x)^{5 / 3}},
$$

where $x=1200 n / \bar{v}_{10} \cdot \bar{v}_{10}$ is the wind speed of standard height. $n$ is the frequency of fluctuating wind.

The harmony superposition method proposed by Shinozuka is a numerical simulation method to simulate the steady random process. According to the theory of Shinozuka, when $N \rightarrow \infty$, velocity time series of fluctuating wind $u_{i}(t)$ can be expressed as follows:

$$
\begin{array}{r}
u_{i}(t) \\
=\sum_{l=1}^{i} \sum_{k=1}^{N}\left|H_{i l}\left(\omega_{k}\right)\right| \sqrt{2 \Delta \omega_{k}} \cos \left[\omega_{k} t-\theta_{i l}\left(\omega_{k}\right)+\varphi_{l k}\right] \\
i=1,2, \ldots, m,
\end{array}
$$

where $N$ is the division numbers of fluctuating wind frequency. $H_{i l}$ is obtained from Cholesky decomposition of the wind cross-spectral density matrix. $\theta_{i l}(\omega)$ is the phase angle between the two different loading points. $\varphi_{l k}$ is the uniformly random numbers in $[0,2 \pi] . \Delta \omega_{k}$ is the frequency increment. $\omega_{k}=k \Delta \omega_{k}-((N-l) / N) \Delta \omega_{k}$.

It is very difficult to simulate the wind velocity history for every node of the transmission tower and line because the nodes of the transmission tower and line are too much. Considering sufficient accuracy, the transmission tower is divided into 13 regions and each region can be simplified as one simulation point shown in Figure 4. The positions of each region center and windward area are listed in Table 1. The middle span and side span of transmission line are divided into 27 and 12 regions, respectively. The spatial correlation function for wind velocities is taken into account in the 


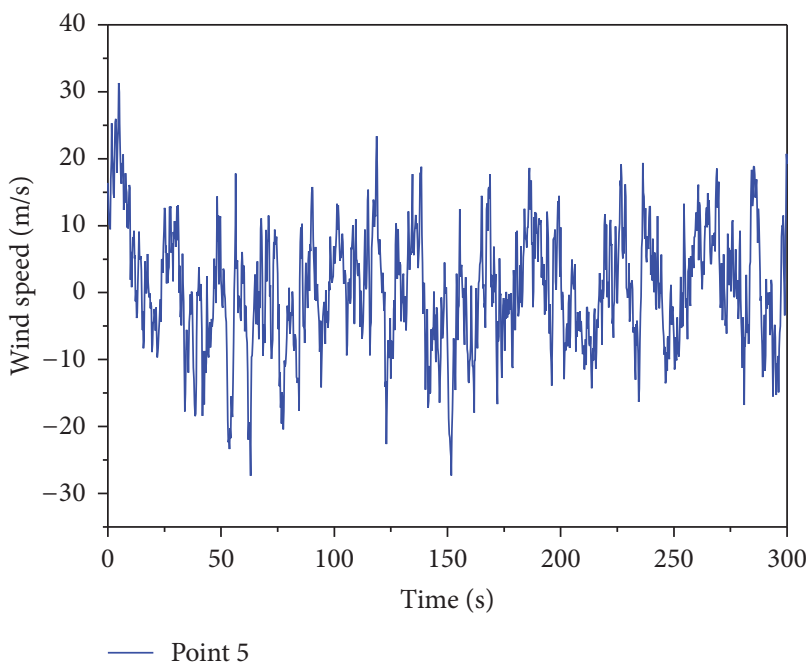

(a) Simulation point 5

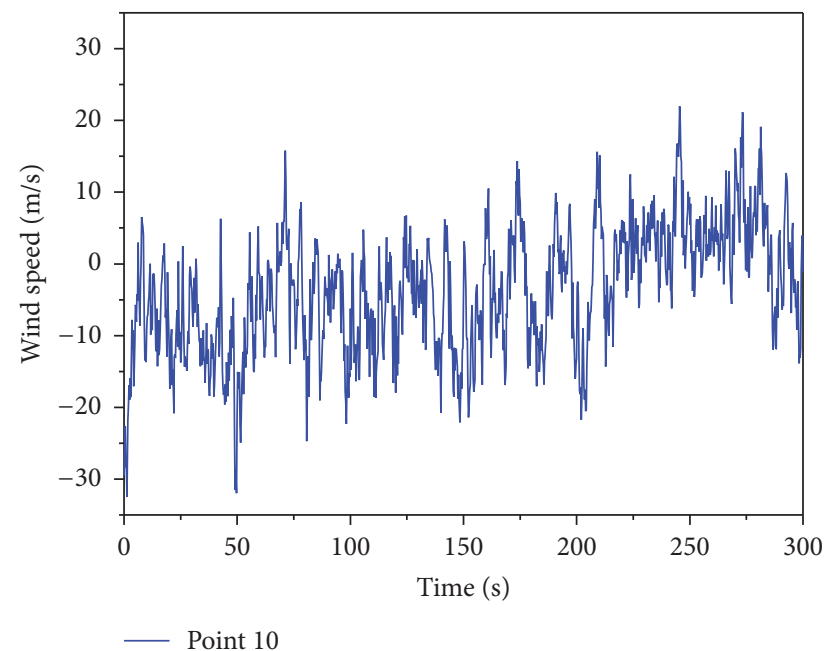

(b) Simulation point 10

FIgURE 6: The simulated fluctuating wind time histories of points 5 and 10.

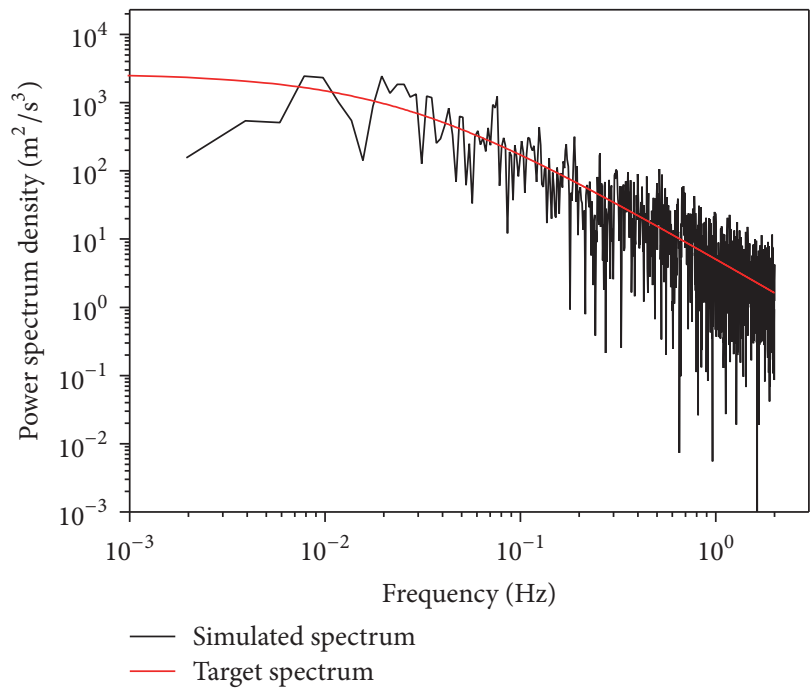

(a) Simulation point 5

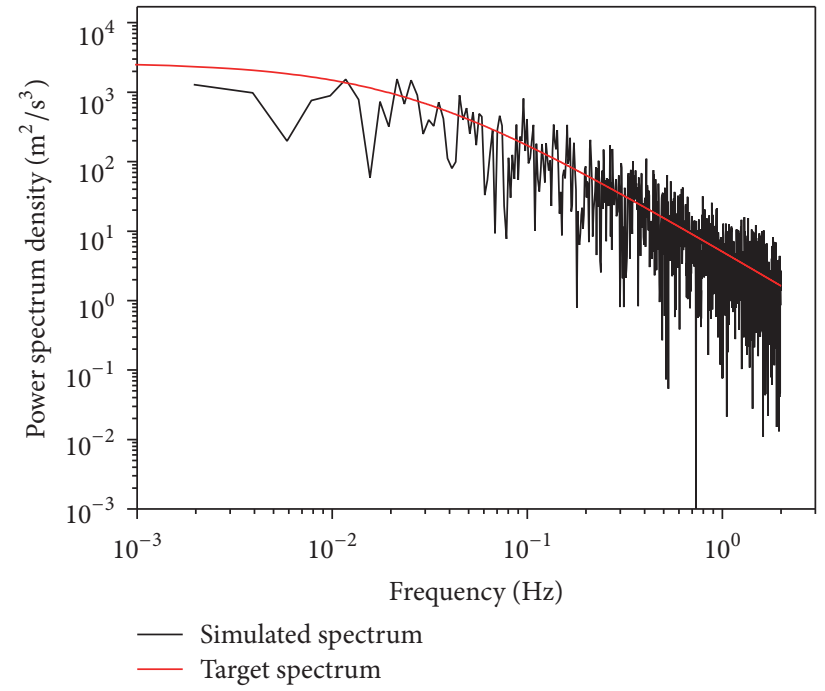

(b) Simulation point 10

FIGURE 7: Comparison between simulated and objective wind spectra.

mathematical model for wind forces acting on lines and towers.

Mean wind speed at $10 \mathrm{~m}$ height is assumed to be $30 \mathrm{~m} / \mathrm{s}$. Based on the above method, the fluctuating wind speeds of wind loads are simulated. The fluctuating wind speed time histories of points 5 and 10 are shown in Figure 6. The comparison between simulated and target spectra is to verify the reliability of the simulation method as shown in Figure 7. It can be seen from the figure that the spectral line trend of simulated spectrum is consistent with that of target spectrum, which illustrates the simulation method is reasonable.

The along-wind loads are calculated by the following:

$$
F(t)=\frac{\mu_{s} A V(t)^{2}}{1.6}
$$

where $A$ is the windward area in Table 1. $\mu_{s}$ is the shape coefficient. The shape coefficients of transmission tower and line are equal to 1.35 and 1.1, respectively. $V(t)$ is the wind speed of simulation point.

\section{Mechanism of the TMD}

4.1. Equations of Motion of a System with TMD under Wind Load. TMD is a dynamic absorber consisting of a mass, spring, and damping. The TMD is considered in the transmission tower only in the paper. The structure with tuned mass damper can be simplified as a single-degree-offreedom system, as shown in Figure 8. The equation of motion of TMD can be written as

$$
m_{d}\left(\ddot{x}_{d}+\ddot{x}\right)+c_{d} \dot{x}_{d}+k_{d} x_{d}=0,
$$




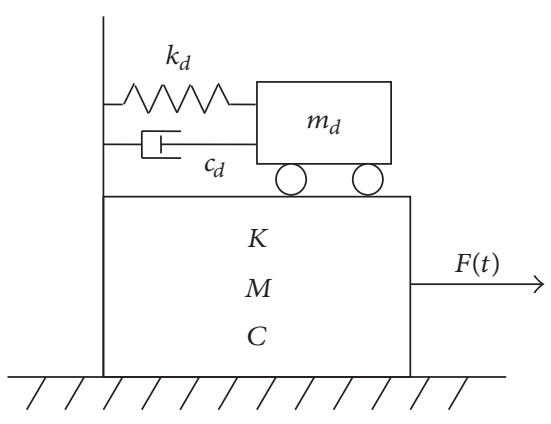

Figure 8: Schematic structure with TMD.

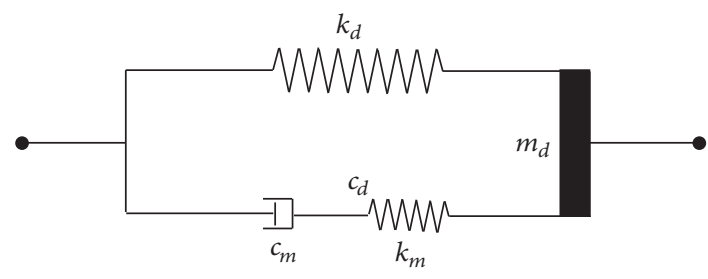

FIgURE 9: Schematic simulation of TMD.

where $x_{d}$ is the displacement of the TMD and $x$ is the displacement of the structure. $m_{d}, c_{d}$, and $k_{d}$ are the mass, damping, and stiffness of the TMD, respectively. The mass, damping, and stiffness of the TMD would be calculated in the next section.

The equation of motion of structure with TMD under wind load can be expressed as

$$
M \ddot{x}+C \dot{x}+K x-c_{d} \dot{x}_{d}-k_{d} x_{d}=F(t),
$$

where $M, C$, and $K$ are the mass, damping, and stiffness of the structure, respectively. The mass, damping, and stiffness of the structure are calculated by the along-wind fundamental vibration mode for wind directions $0^{\circ}$ and $90^{\circ}$, respectively. $F(t)$ is the wind load.

4.2. Finite Element Simulation of TMD. The TMD is simulated by mass element, linear element, and damping element in SAP2000, as shown in Figure 9. The mass, stiffness, and damping of TMD can be derived as

$$
\begin{aligned}
& m_{d}=\mu M, \\
& k_{d}=m_{d} \omega_{d}^{2}, \\
& c_{d}=2 m_{d} \omega_{d} \xi,
\end{aligned}
$$

where $M$ is the mass of the control structure. $\mu$ is the mass ratio. $\omega_{d}$ is the frequency of the control structure. $\xi$ is the damping ratio of the TMD.

The Maxwell calculation model of damping $c_{m}$ and spring $k_{m}$ in series is used to simulate damping $c_{d}$ as shown in Figure 10 [14]. The displacement of the spring $k_{m}$ and

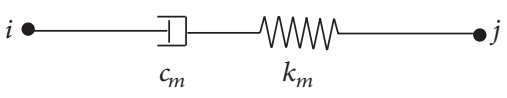

FIGURE 10: Schematic of Maxwell model.

damping $c_{m}$ is defined as $d_{k}$ and $d_{c}$, respectively. The related equations of the Maxwell model can be expressed as

$$
\begin{aligned}
f_{d} & =k_{m} d_{k}=c_{m} \dot{d}_{c}, \\
d & =d_{k}+d_{c},
\end{aligned}
$$

where $d$ is the deformation between $i$ and $j$. When $k_{m}$ is large enough and $d_{k}$ is small enough, $d=d_{c}$ can be obtained. Meanwhile, $f_{d}=c_{m} \dot{d}$ can be derived and $c_{m}$ is the damping of TMD.

\section{Parameters Study of TMD}

The transmission tower-line system models shown in Figure 4 without control and with the TMD are analyzed, respectively. The Newmark- $\beta$ method is applied in the numerical integration. The geometric nonlinearity is taken into account due to large deformation. The damping ratios of the transmission tower and transmission line are assumed to be 0.02 and 0.01 , respectively. The vibration of the first mode of the transmission tower under wind load is controlled by TMD, and the TMD is installed on the top of the transmission tower. To obtain the optimal control parameters, the effects of mass ratio, frequency ratio, and damping ratio are investigated, respectively. The mass ratio between TMD and structure can be defined as $\mu=m_{d} / M \times 100 \%$. The frequency ratio between TMD and structure can be defined as $f=\omega_{d} / \omega_{s}$. The vibration reduction ratio can be defined as

$$
\delta=\frac{R_{0}-R_{1}}{R_{0}} \times 100 \%,
$$

where $R_{0}$ and $R_{1}$ are the response of the transmission tower without and with control, respectively.

5.1. Effect of Mass Ratio. To study the effect of mass ratio between TMD and tower on the vibration reduction ratio, eight different mass ratios are considered in the analysis, $0.5 \%, 1 \%, 2 \%, 3 \%, 4 \%, 5 \%, 6 \%$, and $7 \%$, to cover the range of the mass ratio in the engineering. In all these cases, the frequency ratio between TMD and tower is assumed to be 1 , and the damping ratio of TMD is assumed to be 0.1 .

As shown in Figure 11, the vibration reduction ratios of axial force along the height of tower with different mass ratios are given. It can be seen from the figure that the vibration reduction ratio of axial force of tower under different wind attack angles increases gradually with the increasing mass ratio. The maximum vibration reduction ratio of axial force of tower could exceed 50\% when the mass ratio reaches $7 \%$. The vibration reduction ratios of axial force of tower under $0^{\circ}$ wind attack angle are less than those under $90^{\circ}$ wind attack angle when the mass ratio is less than $4 \%$. However, the vibration reduction ratios of axial force of tower under $0^{\circ}$ 


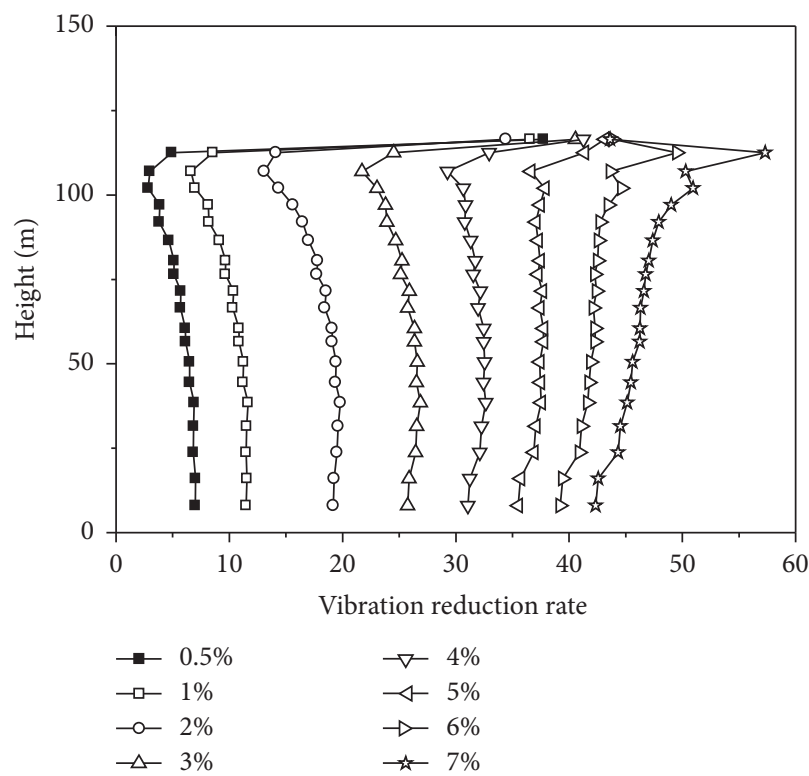

(a) $0^{\circ}$ wind attack angle

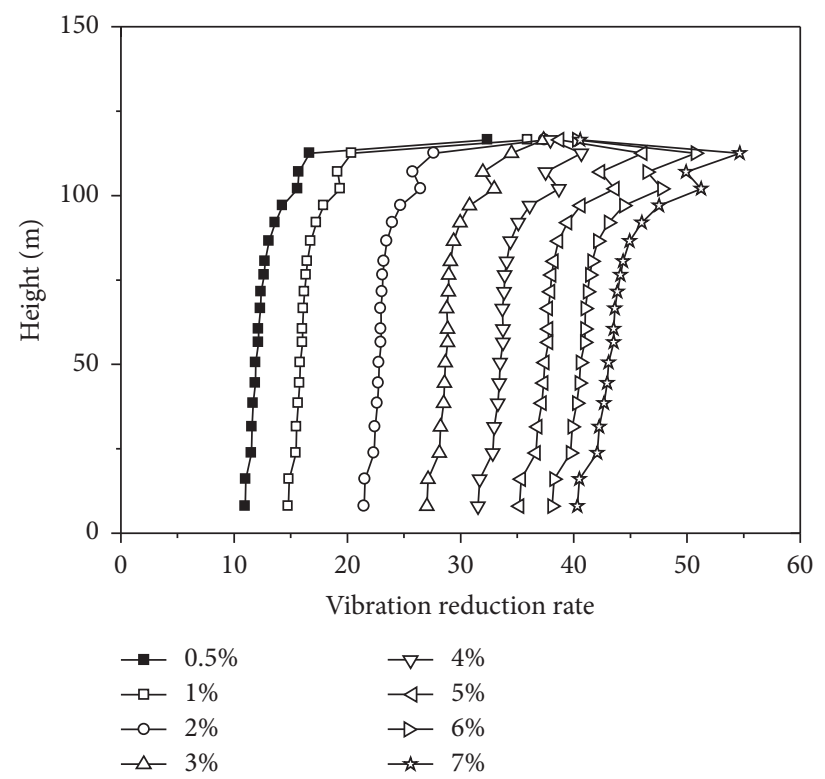

(b) $90^{\circ}$ wind attack angle

FIGURE 11: Vibration reduction ratio of axial force along the height of tower.

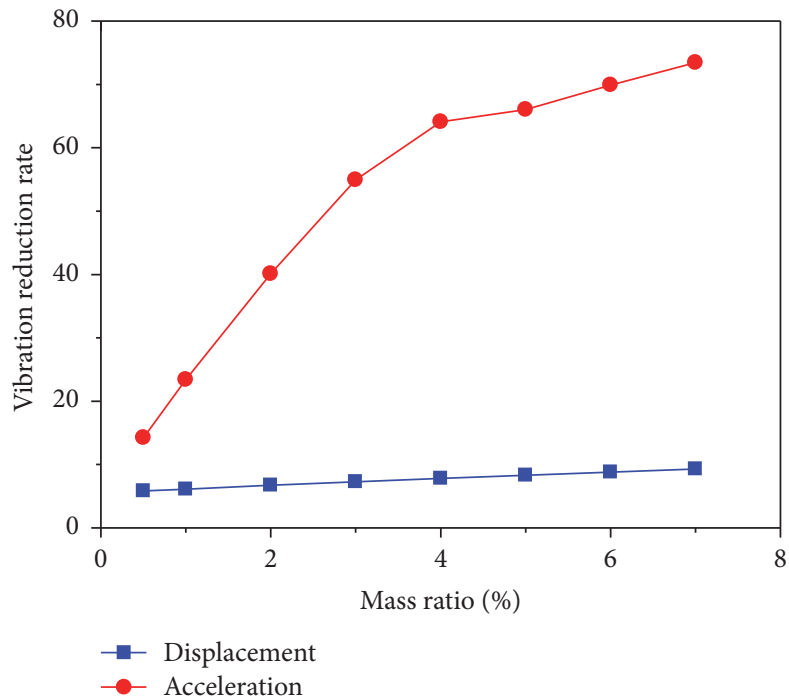

(a) $0^{\circ}$ wind attack angle

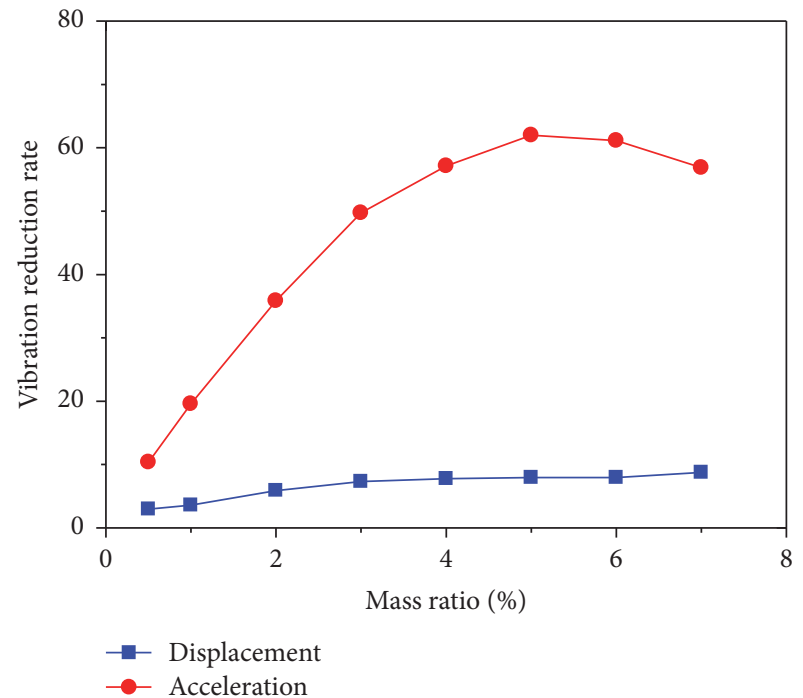

(b) $90^{\circ}$ wind attack angle

FIGURE 12: Vibration reduction ratios of displacement and acceleration at the top of tower.

wind attack angle are close to those under $90^{\circ}$ wind attack angle when the mass ratio is larger than $5 \%$. The results also show that the increasing speed of the vibration reduction ratio of axial force decreases with the increasing mass ratio.

The vibration reduction ratios of displacement and acceleration at the top of tower with different mass ratios under different wind attack angles are shown in Figure 12. As shown in Figure 12(a), the vibration reduction ratios of displacement and acceleration under $0^{\circ}$ wind attack angle have an increasing tendency with the increasing mass ratio. However, the increasing speed of the vibration reduction ratio of acceleration obviously decreases when the mass ratio exceeds $4 \%$. The vibration reduction ratio of displacement is not significant with the increasing mass ratio. It also can be seen from Figure 12(b) that the increasing speeds of the vibration reduction ratios of the displacement and acceleration under $90^{\circ}$ wind attack angle are slow when the mass ratio exceeds $3 \%$. The vibration reduction ratio of acceleration decreases with the increasing mass ratio when the mass ratio exceeds 5\%, and the curve of the vibration reduction ratio of acceleration shows inflection point.

The above analysis shows that the increasing mass ratio has a significant effect on the vibration reduction ratio. The increasing speed of the vibration reduction ratio of tower 


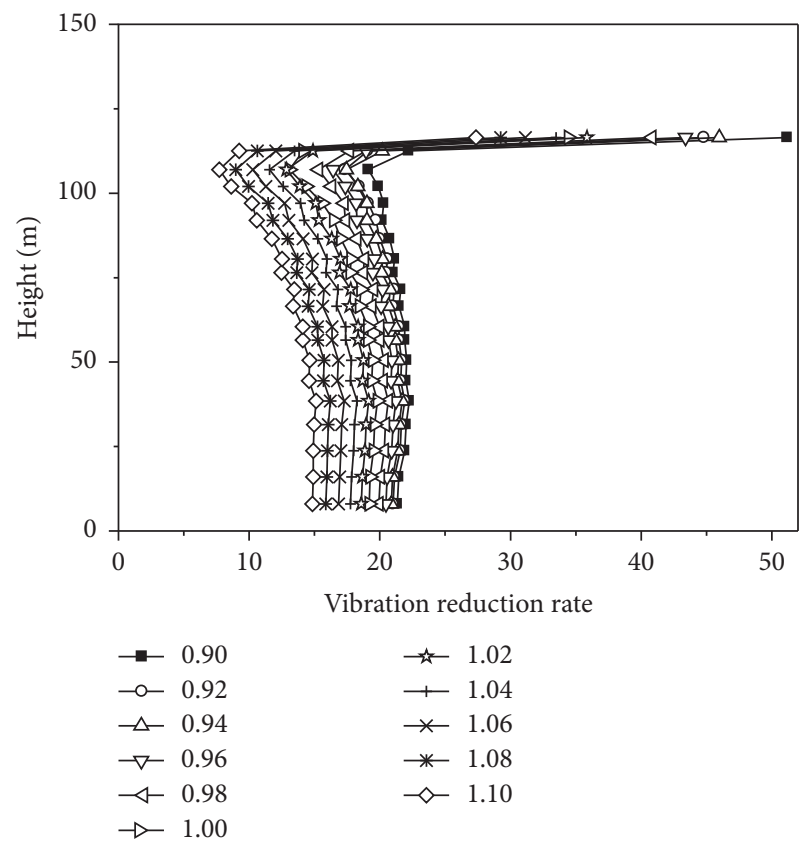

(a) $0^{\circ}$ wind attack angle

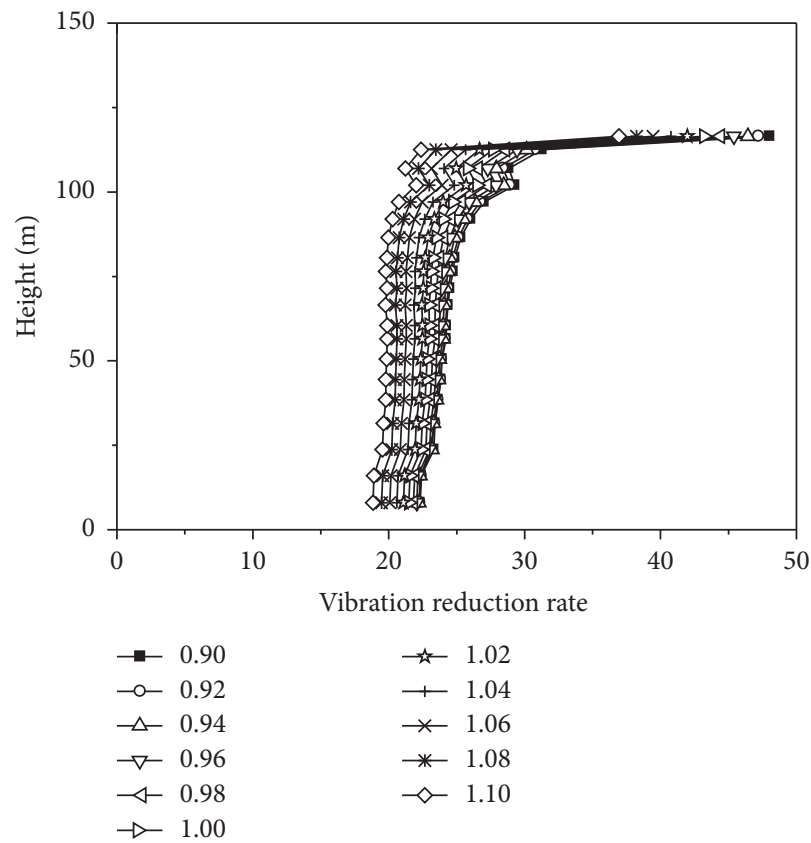

(b) $90^{\circ}$ wind attack angle

FIGURE 13: Vibration reduction ratio of axial force along the height of tower.

under $0^{\circ}$ wind attack angle decreases when the mass ratio exceeds $4 \%$, so the mass ratio of $4 \%$ could be selected as an optimal mass ratio. The increasing speeds of the vibration reduction ratios of tower under $90^{\circ}$ wind attack angle are slow when the mass ratio exceeds $3 \%$, and the mass ratio of $3 \%$ could be selected as an optimal mass ratio.

5.2. Effect of Frequency Ratio. To investigate the effect of frequency ratio between TMD and tower on the vibration reduction ratio, eleven different frequency ratios are considered in the analysis, 0.90, 0.92, 0.94, 0.96, 0.98, 1.00, 1.02, 1.04, $1.06,1.08$, and 1.10. In all these cases, the mass ratio between TMD and tower is assumed to be $2 \%$, and the damping ratio of TMD is assumed to be 0.1 .

The vibration reduction ratios of axial force along the height of tower with different frequency ratios under different wind attack angles are shown in Figure 13. It is clear from Figure 13 that the vibration reduction ratio of axial force decreases gradually with the increasing frequency ratio. It also can be seen from the figure that the change of frequency ratio has a little influence on the vibration reduction ratio of axial force under $90^{\circ}$ wind attack angle. The minimum vibration reduction ratio of axial force exceeds $10 \%$ with the variation of frequency ratios.

The vibration reduction ratios of displacement and acceleration at the top of tower with different frequency ratios under different wind attack angles are shown in Figure 14. It is clear that the vibration reduction ratios of acceleration increase with the increasing frequency ratio. However, the variation tendencies of vibration reduction ratio of displacement under two wind attack angles are different. The vibration reduction ratio of displacement under $0^{\circ}$ wind attack angle decreases with the increasing frequency ratio, but the vibration reduction ratio of displacement under $90^{\circ}$ wind attack angle increases with the increasing frequency ratio.

From the analysis above, it can be seen that the change of frequency ratio has a little influence on the vibration reduction ratio. Considering the vibration reduction ratio of axial force along the height of tower, displacement and acceleration at the top of tower, the frequency ratio of 0.98 could be selected as an optimal frequency ratio.

5.3. Effect of Damping Ratio. To research the effect of damping ratio of TMD on the vibration reduction ratio, eleven different damping ratios are considered in the analysis, 0 , $0.02,0.04,0.06,0.08,0.10,0.12,0.14,0.16,0.18$, and 0.20 . In all these cases, the mass ratio and frequency ratio between TMD and tower are assumed to $2 \%$ and 1 , respectively.

The vibration reduction ratios of axial force along the height of tower with different damping ratios are shown in Figure 15. It is clear from the figure that the vibration reduction ratio of axial force decreases with the increasing damping ratio. The variations of damping ratio have a greater influence on the vibration reduction ratio of axial force under $0^{\circ}$ wind attack angle than that of under $90^{\circ}$ wind attack angle.

Figure 16 shows the vibration reduction ratios of displacement and acceleration at the top of tower under different wind attack angles. The vibration reduction ratio of acceleration decreases gradually with the increasing damping ratio when the damping ratio exceeds 0.02 . The variation of vibration reduction ratio of displacement under $0^{\circ}$ wind attack angle is just opposite to that of under $90^{\circ}$ wind attack angle. The vibration reduction ratio of displacement under $0^{\circ}$ wind attack angle decreases gradually with the increasing damping 


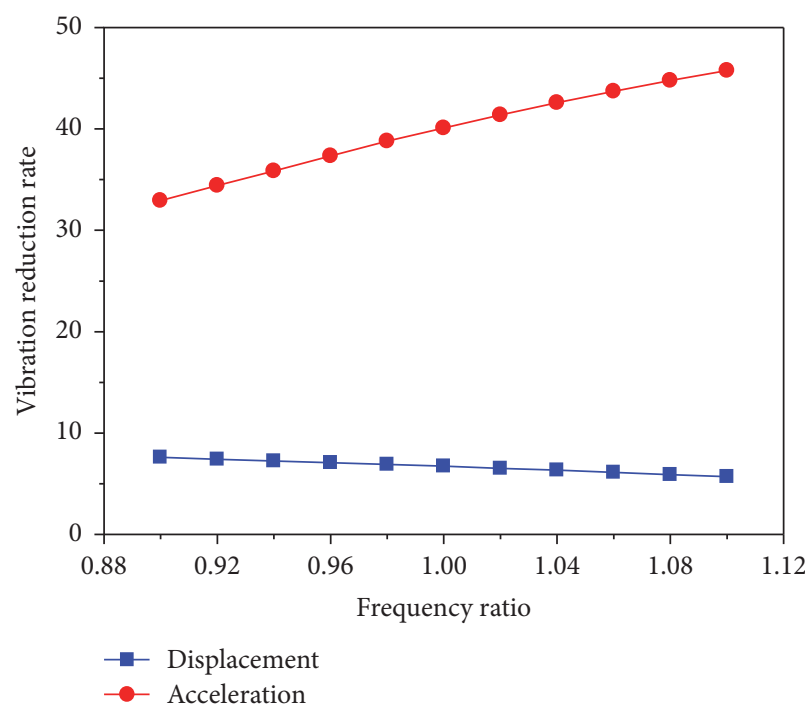

(a) $0^{\circ}$ wind attack angle

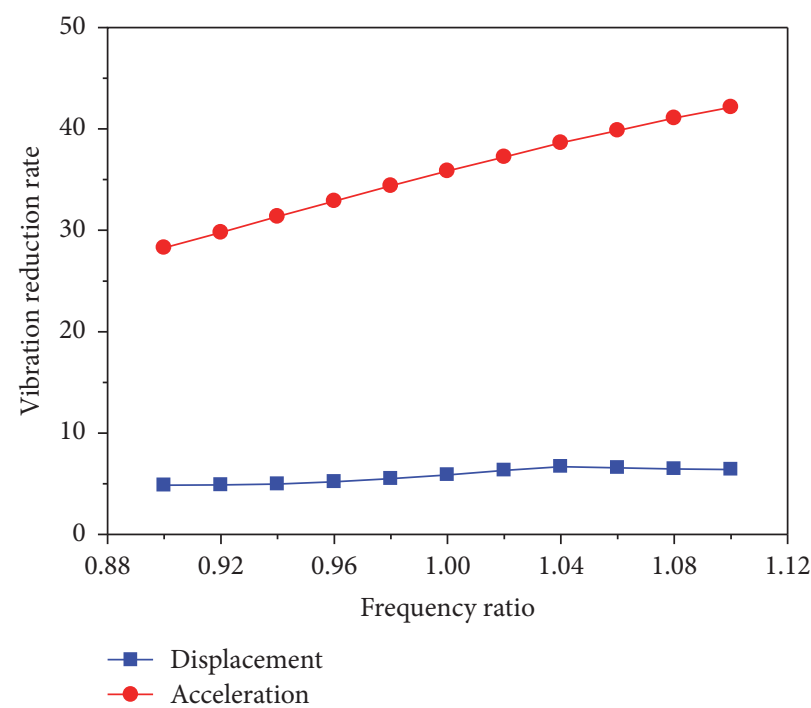

(b) $90^{\circ}$ wind attack angle

FIGURE 14: Vibration reduction ratio of displacement and acceleration at the top of tower.

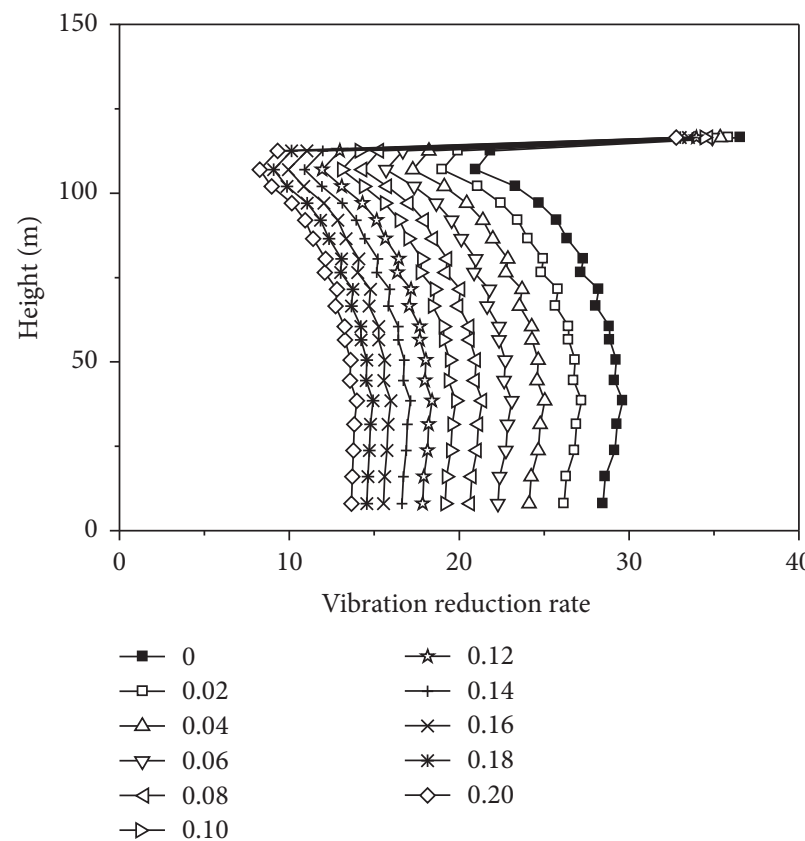

(a) $0^{\circ}$ wind attack angle

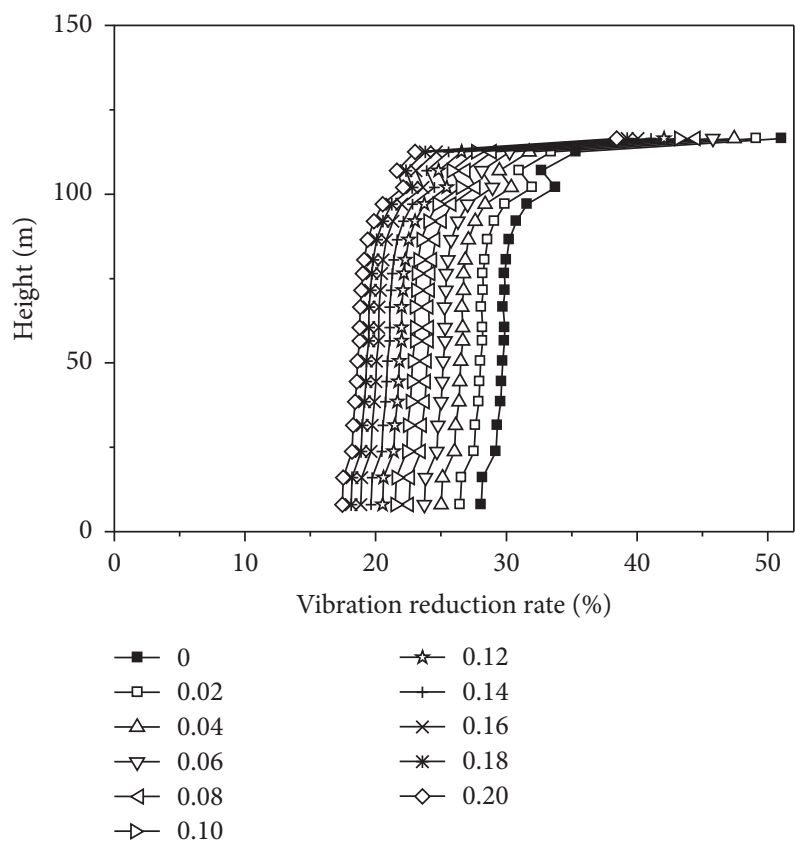

(b) $90^{\circ}$ wind attack angle

FIGURE 15: Vibration reduction ratio of axial force along the height of tower.

ratio, but the vibration reduction ratio of displacement under $90^{\circ}$ wind attack angle increases gradually with the increasing damping ratio.

The above discussion shows that the damping ratio has a greater influence on the vibration reduction ratio under $0^{\circ}$ wind attack angle than that of under $90^{\circ}$ wind attack angle. Considering the vibration reduction ratio of axial force along the height of tower, displacement and acceleration at the top of tower, the optimal damping ratio of 0.08 could be selected as an optimal damping ratio.
In conclusion, the mass ratio has a greater effect on the vibration reduction ratio than those of frequency ratio and damping ratio. The best vibration reduction ratio of TMD is not the frequency ratio of 1 . The optimal parameters of TMD under different wind attack angles are listed in Table 2.

\section{Effect of Sag-Span Ratio}

In this section, the change of the sag of transmission line is discussed based on the optimal parameters of TMD shown 


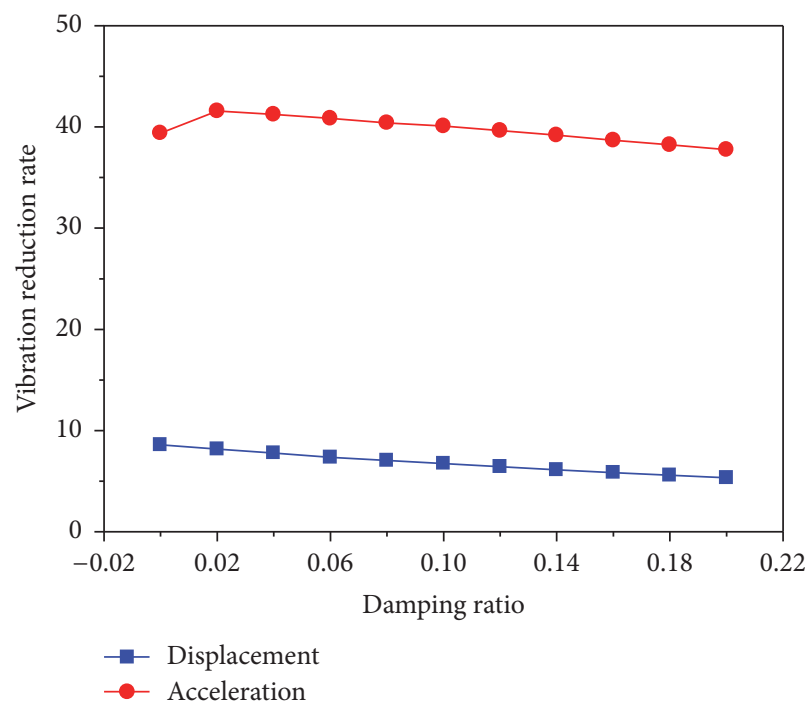

(a) $0^{\circ}$ wind attack angle

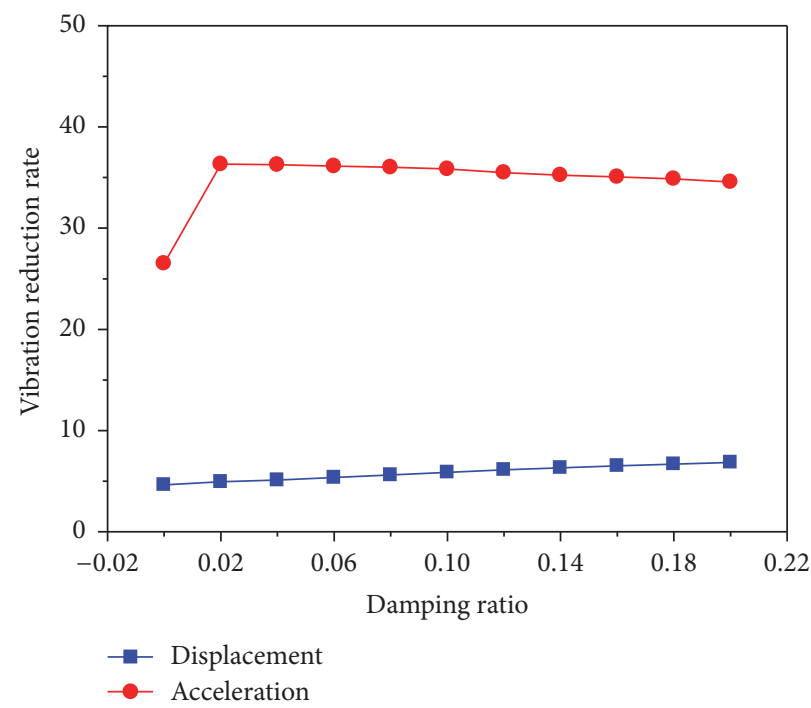

(b) $90^{\circ}$ wind attack angle

FIGURE 16: Vibration reduction ratio of displacement and acceleration at the top of tower.

TABLE 2: Optimal parameters of TMD under different wind attack angles.

\begin{tabular}{lcc}
\hline Optimal parameter & $0^{\circ}$ wind attack angle & $90^{\circ}$ wind attack angle \\
\hline Mass ratio (\%) & $3 \%$ & $4 \%$ \\
Frequency ratio & 0.98 & 0.98 \\
Damping ratio & 0.08 & 0.08 \\
\hline
\end{tabular}

in Table 2. The current state of the sag of transmission line is $55 \mathrm{~m}$ and the span of transmission towers is $1118 \mathrm{~m}$, so the sag-span ratio is 0.049 . The vibration reduction ratios of TMD under different wind attack angles considering the effect of sag-span ratio are analyzed, respectively. The vibration reduction ratios of TMD with different sag-span ratio are listed in Table 3. It can be seen from the table that the sag-span ratio has a little influence on the vibration reduction ratio. Because the span of the transmission towers is very large and the change of the sag of transmission line ranges in 5 meters, the change of sag-span ratio is small. Therefore, the sag-span ratio has an insignificant effect on the vibration reduction ratio of transmission tower when the change of sag-span ratio is not large.

\section{Robustness Study}

To study the robustness of TMD, the case that ice loads are on the transmission tower and line is taken into consideration. The increasing of the cross sectional area of the members, insulators, and transmission lines caused by icing is equivalent to the change of the material density in transmission tower-line system. Meanwhile, the wind loads in each simulation point are varied owing to the increasing of the windshield area. The optimal parameters of TMD under different wind attack angles shown in Table 2 are selected in this section.
As shown in Table 4, the vibration reduction ratios of TMD of the transmission tower-line system without and with considering ice are analyzed, respectively. The thickness of ice is assumed to be $5 \mathrm{~mm}$. It can be seen from Table 4 that the vibration reduction ratios of axial force and acceleration decrease when the ice load is considered, but the vibration reduction ratio of the displacement increases. Owing to the effect of ice, the vibration frequency and wind load of the transmission tower-line system should be changed, and it would affect the vibration reduction ratio. Therefore, the effect of ice should be considered when the robustness study of TMD is carried out.

\section{Conclusion}

The parametric study of tuned mass damper for long span transmission tower-line system under wind loads is carried out. The three-dimensional finite element model of long span transmission tower-line system is established. The wind load time history is simulated by the harmony superposition method. The effects of mass ratio, frequency ratio, damping ratio, the sag of transmission line, and the robustness of TMD are investigated, respectively. Based on above study, the following conclusions are drawn:

(1) The increasing mass ratio has a significant effect on the vibration reduction ratio. The vibration reduction ratios increase with the increasing mass ratio, but the increasing speed of the vibration reduction ratio of tower decreases when the mass ratio exceeds a certain ratio. The mass ratio of $4 \%$ and $3 \%$ could be selected as an optimal mass ratio under $0^{\circ}$ and $90^{\circ}$ wind attack angles, respectively.

(2) The change of the frequency ratio has a little influence on the vibration reduction ratio. The vibration reduction ratios of axial force and acceleration increase 
TABLE 3: Vibration reduction ratio of TMD with different sag-span ratio (\%).

\begin{tabular}{lcccc}
\hline Response & Line sag $(\mathrm{m})$ & Sag-span ratio & Wind angle of $90^{\circ}$ & Wind angle of $0^{\circ}$ \\
\hline \multirow{3}{*}{ Axial force } & 50 & 0.045 & 19.6 & 29.7 \\
& 55 & 0.049 & 17.2 & 28.3 \\
\hline \multirow{3}{*}{ Displacement } & 60 & 0.054 & 49.1 & 30.1 \\
\hline \multirow{3}{*}{ Acceleration } & 50 & 0.045 & 3.8 & 5.7 \\
& 55 & 0.049 & 4.6 & 6.2 \\
& 60 & 0.054 & 46.1 & 5.6 \\
& 50 & 0.045 & 50.2 & 60.1 \\
\end{tabular}

TABLE 4: Vibration reduction ratio of TMD without and with considering ice (\%).

\begin{tabular}{lccc}
\hline Response & Ice thickness $(\mathrm{mm})$ & Wind angle of $90^{\circ}$ & Wind angle of $0^{\circ}$ \\
\hline \multirow{2}{*}{ Axial force } & 0 & 17.2 & 28.3 \\
& 5 & 16.8 & 22.4 \\
\hline \multirow{2}{*}{ Displacement } & 0 & 3.8 & 6.2 \\
\hline \multirow{2}{*}{ Acceleration } & 5 & 6.7 & 7.1 \\
& 0 & 50.2 & 61.3 \\
\hline
\end{tabular}

with the increasing frequency ratio, but the variation tendencies of vibration reduction ratio of displacement under two wind attack angles are different. The frequency ratio of 0.98 could be selected as an optimal frequency ratio under $0^{\circ}$ and $90^{\circ}$ wind attack angles.

(3) The damping ratio has a greater influence on the vibration reduction ratio under $0^{\circ}$ wind attack angle than that of under $90^{\circ}$ wind attack angle. The vibration reduction ratios of axial force and acceleration decrease with the increasing damping ratio, while the variation of vibration reduction ratio of displacement under $0^{\circ}$ wind attack angle is just opposite to that of under $90^{\circ}$ wind attack angle. The damping ratio of 0.08 could be selected as an optimal damping ratio under $0^{\circ}$ and $90^{\circ}$ wind attack angles.

(4) The sag-span ratio has an insignificant effect on the vibration reduction ratio of transmission tower when the change of sag-span ratio is not large. The change of vibration frequency and wind load of the transmission tower-line system should be varied due to the effect of ice, and the vibration reduction ratio would be changed. The effect of ice should be considered when the robustness study of TMD is carried out.

\section{Competing Interests}

The authors declare that there is no conflict of interests regarding the publication of this paper.

\section{Acknowledgments}

This research is supported by Ph.D. Programs Foundation of Ministry of Education of China Project under Grant no.
20120131120036 and Shandong Provincial Natural Science Foundation of China under Grant no. ZR 2012EEQ005.

\section{References}

[1] H.-N. Li, W.-L. Shi, G.-X. Wang, and L.-G. Jia, "Simplified models and experimental verification for coupled transmission tower-line system to seismic excitations," Journal of Sound and Vibration, vol. 286, no. 3, pp. 569-585, 2005.

[2] J.-H. Park, B.-W. Moon, K.-W. Min, S.-K. Lee, and C. K. Kim, "Cyclic loading test of friction-type reinforcing members upgrading wind-resistant performance of transmission towers," Engineering Structures, vol. 29, no. 11, pp. 3185-3196, 2007.

[3] J. C. Wu and J. N. Yang, "Active control of transmission tower under stochastic wind," Journal of Structural Engineering, vol. 124, no. 11, pp. 1302-1312, 1998.

[4] J.-C. Wu and J. N. Yang, "LQG control of lateral-torsional motion of Nanjing TV transmission tower," Earthquake Engineering and Structural Dynamics, vol. 29, no. 8, pp. 1111-1130, 2000.

[5] R. C. Battista, R. S. Rodrigues, and M. S. Pfeil, "Dynamic behavior and stability of transmission line towers under wind forces," Journal of Wind Engineering and Industrial Aerodynamics, vol. 91, no. 8, pp. 1051-1067, 2003.

[6] Y.-F. He, W.-J. Lou, B.-N. Sun, S.-C. Yu, Y. Guo, and Y. Ye, "Wind-induced vibration control of long span transmission tower with suspended mass pendulums," Journal of Zhejiang University (Engineering Science), vol. 39, no. 12, pp. 1891-1896, 2005.

[7] B. Chen, J. Zheng, and W. L. Qu, "Control of wind-induced response of transmission tower-line system by using magnetorheological dampers," International Journal of Structural Stability and Dynamics, vol. 9, no. 4, pp. 661-685, 2009.

[8] B. Chen, X. Xiao, P.-Y. Li, and W.-L. Zhong, "Performance evaluation on transmission tower-line system with passive 
friction dampers subjected to wind excitations," Shock and Vibration, vol. 2015, Article ID 310458, 13 pages, 2015.

[9] P. Zhang, L. Ren, H. Li, Z. Jia, and T. Jiang, "Control of windinduced vibration of transmission tower-line system by using a spring pendulum," Mathematical Problems in Engineering, vol. 2015, Article ID 671632, 10 pages, 2015.

[10] L. Tian and X. Gai, "Wind-induced vibration control of power transmission tower using pounding tuned mass damper," Journal of Vibroengineering, vol. 17, no. 7, pp. 3693-3701, 2015.

[11] M. Shinozuka, "Simulation of multivariate and multidimensional random processes," The Journal of the Acoustical Society of America, vol. 49, no. 1, pp. 357-368, 1971.

[12] M. Shinozuka and C.-M. Jan, "Digital simulation of random processes and its applications," Journal of Sound and Vibration, vol. 25, no. 1, pp. 111-128, 1972.

[13] J. C. Kaimal, J. C. Wyngaard, Y. Izumi, and O. R. Coté, "Spectral characteristics of surface-layer turbulence," Quarterly Journal of the Royal Meteorological Society, vol. 98, no. 417, pp. 563-589, 1972.

[14] R. Rana and T. T. Soong, "Parametric study and simplified design of tuned mass dampers," Engineering Structures, vol. 20, no. 3, pp. 193-204, 1998. 


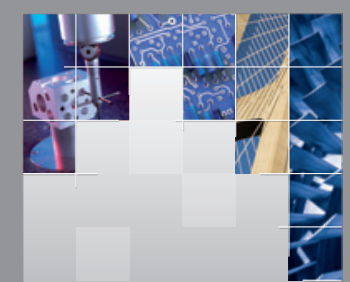

\section{Enfincering}
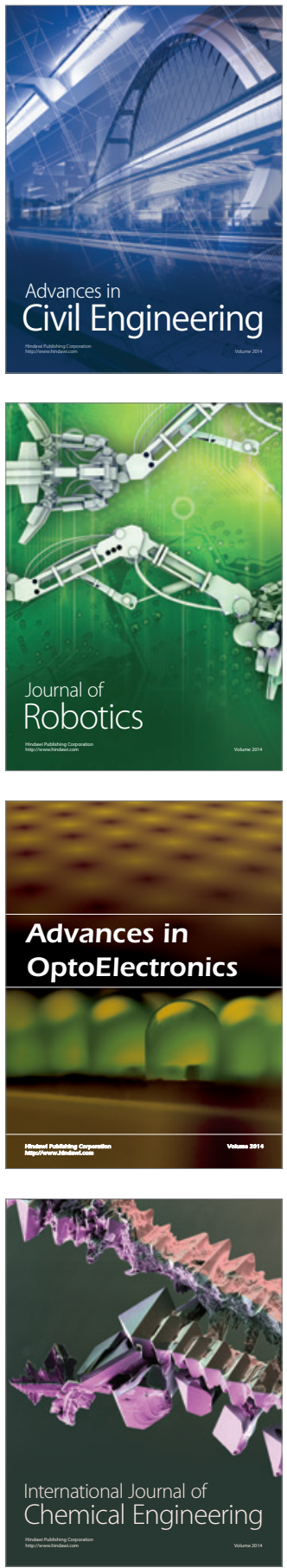

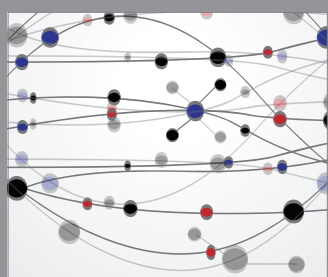

The Scientific World Journal

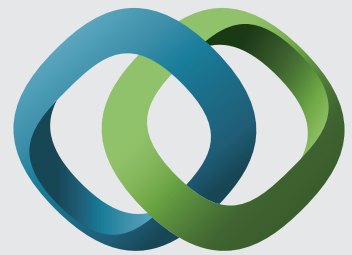

\section{Hindawi}

Submit your manuscripts at

http://www.hindawi.com
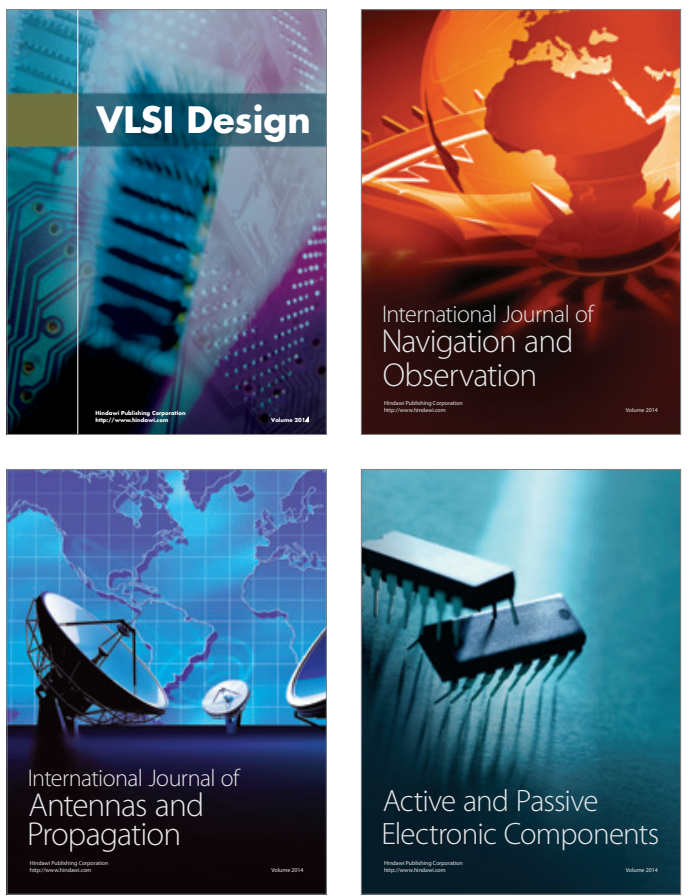
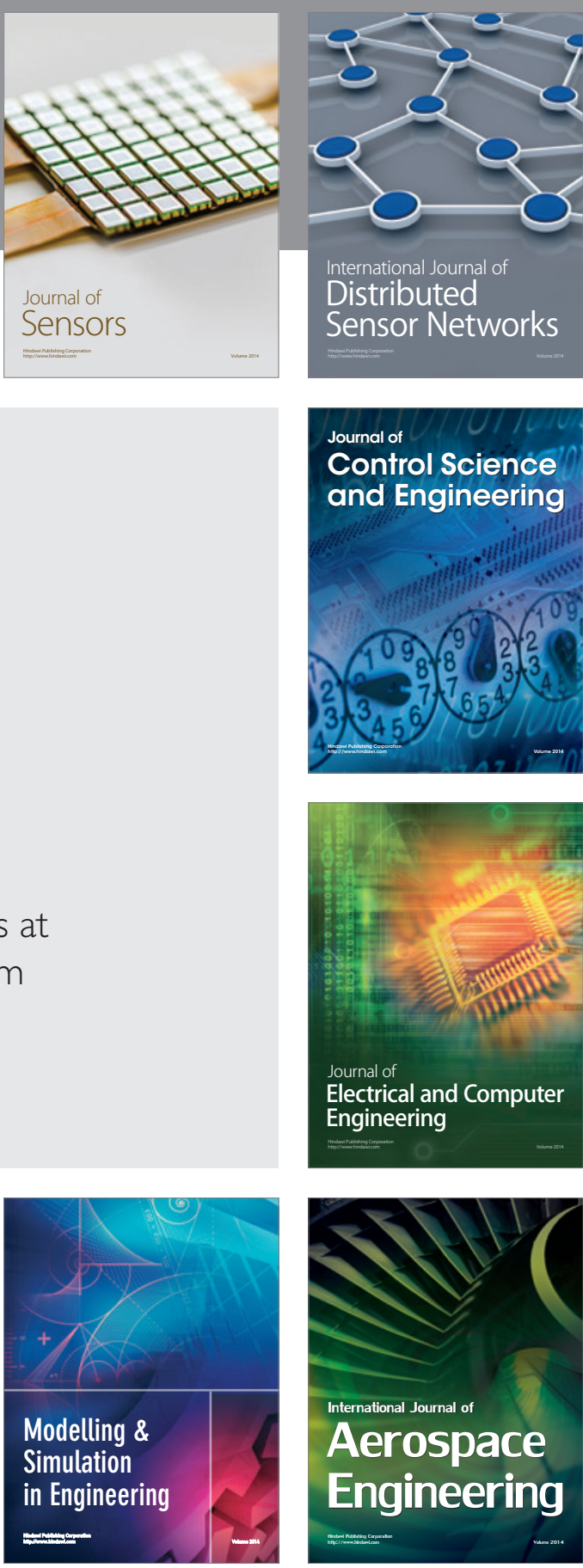

International Journal of

Distributed

Sensor Networks

Journal of

Control Science

and Engineering
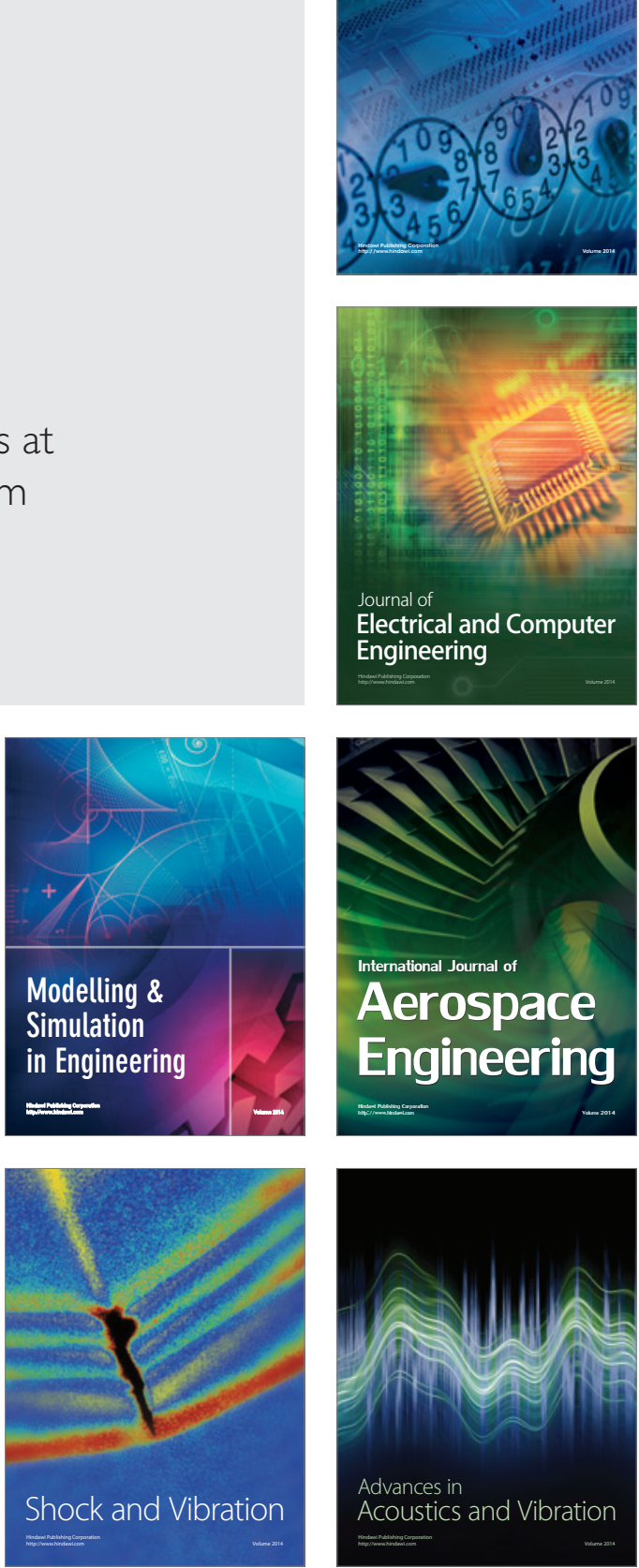